\title{
Indústria Farmacêutica no Brasil: Evolução Histórica, Capacitação Competitiva e Políticas Industriais
}

\section{Rafaela Cristina Pereira Silva' Thiago Caliari²}

\begin{abstract}
RESUMO: O objetivo desse trabalho é estudar o processo de desenvolvimento da indústria farmacêutica brasileira e as implicações das políticas públicas, especialmente as políticas industriais, na conformação desse setor no país. Os resultados apontam que nos últimos anos pode ser verificada uma nova conformação da estrutura industrial nacional, com aumento de relevância das empresas nacionais e novas possibilidades de desenvolvimento dessas empresas pautadas no desenvolvimento de produtos biotecnológicos. Ademais, uma conexão maior entre a indústria e demais agentes importantes para o seu desenvolvimento parece estar sendo gerada com as políticas industriais ativas praticadas pelo governo federal.
\end{abstract}

Palavras - chave: indústria farmacêutica, desenvolvimento setorial, política industrial.

Classificação JEL: L6, L52, I18.

Pharmaceutical Industry in Brazil: Historical Evolution, Competitiveness and Industrial Policies

\begin{abstract}
The goal of this study is to investigate the process of the Brazilian pharmaceutical industry's development and the implications of the public politics, particularly the industrial policy towards resignation in this sector in Brazil. The results point that in the last years can be verified a new conformation of the national industrial structure with increasing relevance of domestic enterprises and new possibilities for these guided companies of developing biotechnological products. Moreover, there seems to be a connection between a bigger industry with other important agents for the development and the policy implemented by the federal government.
\end{abstract}

Keywords: pharmaceutical industry, sectoral development, industrial policy.

1 Consultora - Assessoria e Consultoria Financeira (Ernst \& Young). E-mail: rafaela.pereira@br.ey. com.

2 Professor Adjunto (Instituto Tecnológico da Aeronáutica e Unifal/MG). E-mail: thicaliari@ yahoo.com.br. 


\section{Introdução}

Uma característica particular da indústria farmacêutica compreende sua influência tanto no âmbito econômico quanto na esfera social. Ao mesmo tempo em que uma política industrial pode alterar a dinâmica competitiva do mercado, é capaz de proporcionar qualidade de vida para a população por meio do acesso a medicamentos. Assim, a indústria farmacêutica se mostra apropriada a atrair a atenção do governo por meio de políticas públicas (PALMEIRA FILHO et al., 2012).

No Brasil, a indústria farmacêutica tem se mostrado foco das ações de política industrial nos últimos anos. Essas iniciativas do governo são principalmente de cunho evolucionário, por ser considerado um setor science based, de acordo com a taxonomia de Pavitt (1984), ou seja, um setor que possui um claro relacionamento entre ciência e tecnologia (MAGALHÃES, 2006).

Diante da relevância do tema proposto, o presente trabalho realiza um estudo da evolução da indústria farmacêutica nacional, destacando as particularidades inerentes a políticas públicas e a iniciativa privada desde o começo do século XX. O objetivo é entender o ambiente estrutural no qual se conformou o padrão concorrencial que se encontram as empresas da indústria farmacêutica brasileira no período atual. Assim, pretende-se verificar a influência de políticas industriais, comerciais e de assistência à saúde no setor industrial farmacêutico nacional, respondendo perguntas sobre os impactos dessas políticas. A hipótese que orienta este estudo é de que tais políticas de fomento da indústria farmacêutica contribuíram ativamente para o entendimento da capacidade produtiva e tecnológica das empresas nacionais no período atual.

Além desta introdução, o trabalho está organizado em 3 tópicos. O tópico 1 apresenta o histórico e a evolução da indústria farmacêutica no Brasil. O tópico 2 tem como objetivo apresentar as mudanças institucionais a partir da década de 1990. No tópico 3 são analisadas as principais políticas industriais a partir de 2003 e seus impactos na configuração da indústria farmacêutica nacional de forma recente.

Por fim, a discussão e as considerações finais apresentam os resultados, as contribuições e as limitações das políticas industriais na conformação da indústria farmacêutica brasileira, bem como as perspectivas para o setor, que aparecem inseridas em um cenário otimista com vistas à capacitação tecnológica e biotecnológica.

\section{A indústria farmacêutica no Brasil: histórico e evolução}

O início das operações das empresas atuantes na indústria farmacêutica no Brasil seguiu a evolução das empresas internacionais, tendo sua origem ligada ao surgimento das boticas, que basicamente elaboravam medicamentos para contribuir no tratamento de enfermidades das unidades familiares. $\mathrm{O}$ profissional boticário, responsável pela manipulação dos medicamentos, realizava a atividade na frente do paciente de acordo com a farmacopeia e a prescrição médica. Com o tempo, esse 
cenário evoluiu para o surgimento de novos tipos de estabelecimentos, justamente as farmácias e os Laboratórios Industriais Farmacêuticos (SINDUSFARMA, 2014; FERST, 2013; CRFSP, 2014).

À época da proclamação da República, em meados de 1889, já havia 35 laboratórios farmacêuticos no Brasil. Alguns de relevante valor nacional, como os Institutos de Patologia de Manguinhos, o Butantan e o Pasteur, que produziam medicamentos de origem vegetal, mineral e até animal; tais laboratórios se constituíam como instituições públicas de pesquisa, financiados, pelo investimento estatal (RIBEIRO, 2001). A evolução das atividades farmacêuticas que se segue a partir daí até a Primeira Guerra Mundial, em 1914, é caracterizada pela incipiente importação de medicamentos e pelo aparecimento de especialidades farmacêuticas nacionais, expressadas pelos farmacêuticos ou preparadas nas embrionárias empresas no fundo das boticas (SINDUSFARMA, 2014).

Durante a Primeira Guerra Mundial, a indústria de matérias-primas farmacêuticas, a indústria farmoquímica, vivenciou um crescimento importante que deu suporte à evolução da indústria farmacêutica nacional (LEMOS, 2008). A inviabilidade das importações de farmoquímicos durante a Primeira Guerra Mundial proporcionou um avanço na indústria local, com a demanda interna por princípios ativos garantida, de modo que, já em 1920 podiam ser encontradas 186 empresas nesse setor (CRFSP, 2014).

A década de 1930 é considerada o marco inicial da indústria farmacêutica no Brasil, compreendendo a constituição das primeiras empresas do setor com características industriais e a implantação de instituições de pesquisa e produção de medicamentos para combater os problemas de saúde pública (PALMEIRA FILHO; PAN, 2003; BERMUDEZ, 1994). Mesmo assim, de um modo geral, até 1939 a indústria farmacêutica nacional pode ser considerada inexpressiva, a se comparar com as empresas de nações desenvolvidas (SINDUSFARMA, 2014).

Foi nas décadas de 1940 e 1950 que houve as políticas promotoras da instauração das primeiras firmas multinacionais no país e, a chamada internacionalização da indústria (PALMEIRA FILHO; PAN, 2003). Segundo Lobo (2013), o processo de desenvolvimento da indústria farmacêutica se deu associado ao crescimento industrial total do país e às políticas públicas dedicadas a impulsionar esse crescimento. A indústria química e farmacêutica cresceu 10,5\% entre 1939 e 1952.

Entretanto, o crescimento do parque industrial não foi seguido por um processo de transferência de tecnologia; estas continuavam a serem desenvolvidas nas matrizes externas dessas firmas multinacionais, em uma estratégia denominada P\&D in house (BERMUDEZ, 1994). Os anos 1950 foram marcados pelo agravamento da dependência externa de tecnologia de desenvolvimento de novos medicamentos. Concomitante a isso, a abertura da economia no governo JK agrava o atraso no desenvolvimento das empresas farmacêuticas nacionais; algumas empresas locais fundiram-se com estrangeiras e outras foram vendidas (LEMOS, 2008). A desnacionalização ainda era facilitada pela falta de uma política deliberada do 
governo por meio do Banco Nacional de Desenvolvimento Econômico (BNDE), principal órgão de estímulo à indústria no Brasil, que não considerava a indústria farmacêutica uma prioridade de política industrial para aportes financeiros (BERMUDEZ, 1994).

Nos anos 1960, as firmas estrangeiras passaram a liderar o mercado nacional em razão de suas competências na oferta de medicamentos complexos e sofisticados, fatores que a indústria brasileira tinha dificuldade em seguir pela baixa inserção tecnológica presente em seus produtos (LEMOS, 2008). Em 1971, a promulgação do Código de Propriedade Industrial (Lei 5.772, de 21.12.1971) modificou o cenário competitivo, pois o mesmo não reconhecia o direito patentário de produtos químicos e de tecnologias para sua obtenção (PALMEIRA FILHO; PAN, 2003). A partir daí, segundo Lemos (2008), as empresas brasileiras se empenharam no P\&D por meio de engenharia reversa, mas, ao mesmo tempo, a estratégia das empresas multinacionais se modificou, ampliando a aquisição de empresas nacionais a fim de diminuir a concorrência potencial (LEMOS, 2008).

$\mathrm{Na}$ década de 1970, algumas atuações governamentais buscaram o desenvolvimento e diminuição da dependência externa do setor industrial farmacêutico, como a criação da Central de Medicamentos (CEME), em 1971, e da Companhia de Desenvolvimento Tecnológico (Codetec), em 1976, uma empresa privada, mas incorporada na agenda de ações do governo (BERMUDEZ, 1994). A CEME abarcava, em seu início, propostas de investimento em pesquisa e desenvolvimento de forma integrada com a política de medicamentos do país e, no entanto, se limitou à aquisição centralizada de medicamentos devido às limitações financeiras e esquemas de corrupção denunciados no Governo Federal. O funcionamento da Codetec, da mesma forma, não ocorreu de modo adequado. Essa empresa, que tinha como prioridade o desenvolvimento de processos no campo de síntese química de fármacos, passou por dificuldades de repasse financeiro por parte do Estado e encontrou rejeição em alguns setores governamentais, uma vez que a aquisição de medicamentos pelo governo constituía uma tradicional forma de corrupção (BERMUDEZ, 1994). Desse modo, é possível depreender que o país perdeu uma janela de oportunidade que por meio dessas duas intervenções - associadas aos demais apoios mencionados no texto - poderiam dar suporte à indústria nacional.

Já nos anos 1980, a política desenvolvimentista preconizada pelo processo de substituição de importações, praticada desde os anos 1930, começa a dar lugar a outras estratégias e necessidades macroeconômicas, em especial a inflação, o controle das contas públicas e do balanço de pagamentos. Assim, as diversas medidas de controle de preços praticadas a partir de 1986 incidiram diretamente sobre o preço dos medicamentos (LOBO, 2013).

Porém, em contrapartida à redução de lucratividade das empresas frente às políticas de controle de preços, em 1984 é lançada a Portaria Interministerial no 4 , de 3.10.1984, dos Ministérios da Saúde (MS) e Ministério da Indústria e Comércio (MIC), que foi responsável por definir instrumentos de estímulo e assistência à ati- 
vidade produtiva nacional de fármacos, de forma a estabelecer normas de concessão de licenças para a fabricação de compostos utilizados na produção de medicamentos, além de proibir a importação de fármacos que fossem produzidos internamente (LOBO, 2013; LEMOS, 2008; PALMEIRA FILHO; PAN, 2003).

Entretanto, os objetivos traçados com o lançamento dessa legislação não foram alcançados, uma vez que, a abertura comercial nos anos 1990 permitiu a ampliação das importações de fármacos, ocasionando a suspensão de diversos projetos de produção desses insumos no país (PALMEIRA FILHO; PAN, 2003).

Além disso, a persistência desse esforço de política industrial foi minada pelo lobby ativo das empresas transnacionais e, de acordo com Lobo (2013), a força conjunta dessas duas ações - políticas liberais e lobby - efetivam a conformação estrutural da indústria a favor das empresas transnacionais que se vislumbra no início da década de 90 .

\section{Mudanças institucionais a partir da década de 90}

A conformação estrutural da indústria farmacêutica nacional passa por mudanças ao longo da década de 1990. Nesse período, a estrutura da indústria farmacêutica esteve fortemente ligada às denominadas políticas industriais horizontais, que causaram grande impacto no setor farmacêutico, apoiadas na teoria central de que a realocação de recursos entre setores tende a criar a melhor configuração industrial (RUIZ et al., 2011).

Conforme Gadelha (2003), o Brasil seguiu, de forma tardia, a orientação dos países desenvolvidos, embora em condições históricas e estruturais particulares. Destacam-se abaixo alguns eventos importantes na década.

\subsection{Abertura comercial e financeira}

O início da década de 90 foi marcado pela adequação nacional aos ditames do Consenso de Washington. A liberalização comercial foi um movimento que incluía fundamentalmente a redução das tarifas alfandegárias de forma gradual e a redução ou remoção das barreiras não tarifárias (CALIARI e RUIZ, 2013).

Quanto à reforma tarifária, as tarifas de importação da indústria farmacêutica foram reduzidas de forma progressiva de 60\%, em 1990, chegando a 14\% em 1995. Apesar dessa situação, "o padrão do comércio internacional de fármacos e medicamentos não sofreu alteração significativa, permanecendo o comércio matriz-filial apoiado nos preços de transferência” (TRAJANO DA SILVA, 2003, p. 15).

Já no plano das barreiras não tarifárias, a extinção do Anexo C da Câmara de Comércio Exterior (CACEX) do Banco do Brasil, que abrangia os produtos favorecidos pela Portaria $\mathrm{n}^{\circ}$ 04, culminou no término da reserva de mercado garantida pelo governo à indústria farmoquímica nacional. As empresas e laboratórios multinacionais passaram a importar seus insumos diretamente de suas sedes como forma de contenção de gastos, deixando de consumir das firmas locais. 
No nível microeconômico, as firmas locais reduziram o grau de integração vertical, uma vez que a concorrência passou a determinar maior articulação com o comércio exterior. Além disso, as reformas implementadas como estímulo à competitividade, foram responsáveis por ampliar a importação de bens de capital e matéria-prima, em detrimento da produção local e dos esforços tecnológicos inerentes à atividade produtiva (MOTA; CASSIOLATO; GADELHA, 2012). Ao mesmo tempo, o cenário competitivo local foi prejudicado principalmente nas áreas de maior demanda tecnológica, caso da indústria em questão. Nesse sentido, o mercado brasileiro não oferecia incentivos à produção nacional, o que determinou um grande aumento das importações e, por conseguinte, o agravamento da posição externa da indústria (GADELHA, 2002).

Segundo Oliveira (2005), somente na área da química fina 1.096 unidades de produção foram fechadas, além de 355 projetos cancelados. De forma mais específica, no setor de farmoquímicos, 407 unidades foram paralisadas, e 110 unidades não implementadas.

Em suma, os resultados foram a estagnação da produção nacional de medicamentos, ao mesmo tempo em que as importações aumentavam de forma acelerada, tanto no segmento de insumos quanto na área de medicamentos prontos (HASENCLEVER, 2002).

\subsection{Liberalização dos preços}

Além da abertura comercial e financeira, a indústria farmacêutica nacional enfrentou um processo de liberalização dos preços em 1991 e 1992, caracterizado principalmente pela desintegração dos mecanismos de regulação por parte do Estado, controlados desde a década de 1970 (ISSE, 2011).

Segundo Capanema e Palmeira Filho (2004), de forma específica para a indústria farmacêutica, em meados de 1990, foi estabelecida uma medida que determinava o controle de preços somente para os medicamentos de uso contínuo. Essa situação conservou-se até fevereiro de 1991, quando ocorreu congelamento geral de preços deliberado pelo Plano Collor II, que depois de finalizado deu início ao movimento de liberalização dos preços. No fim de 1991 optou-se pela liberalização gradual, por classes terapêuticas (TRAJANO DA SILVA, 2003).

Os preços dos medicamentos seguiram livres até 1994, sendo estabelecida uma regulação que determinava reajustes periódicos, seguido até 1996. Após esse período, os medicamentos mais uma vez passaram pela liberalização dos preços, até o final de 1998. Nessa conjuntura, com os preços da maioria dos medicamentos liberados, o resultado observado foi uma melhoria na rentabilidade das firmas farmacêuticas que, por sua vez, pode ser confirmada pelo fato de que o número de unidades vendidas não sofreu alteração importante em relação ao período anterior à liberalização dos preços (RUIZ et al., 2011).

O preço médio dos medicamentos se elevou de forma substancial, porém, com aumento da oferta externa em detrimento da produção local. Desse modo, a liberali- 
zação acabou por gerar um efeito contrário ao que era esperado em tal caso, ou seja, de que seria gerada uma concorrência setorial capaz de regular os preços, aumentar a qualidade e ampliar a oferta doméstica (RUIZ et al., 2011; FRENKEL, 2002).

\subsection{Lançamento do plano real e a estabilização macroeconômica}

O estabelecimento do Plano Real no Brasil conduziu a economia brasileira a importantes transformações macroeconômicas. O pacote de políticas para estabilização compreendia a abertura comercial, explicitada anteriormente, e a sobrevalorização da moeda nacional. Essas medidas, aliadas à melhoria na distribuição de renda e ao aumento do consumo da população, permitidos pela estabilização econômica, levaram a uma ampliação intensa das importações, frente ao baixo crescimento das exportações decorrente da redução da oferta de produtos. $\mathrm{O}$ resultado disso foi um período assinalado por contínuos déficits na balança comercial a partir de 1994 (CASTILHO, 2011).

No que se refere de forma específica à indústria farmacêutica, esse quadro comercial deficitário foi, em parte, devido ao ritmo acelerado em que cresciam as importações de fármacos e medicamentos (OLIVEIRA, 2005).

Por outro lado, a estabilização dos preços a partir do Plano Real favoreceu a recuperação da rentabilidade do âmbito farmacêutico, ao mesmo tempo em que assegurava a ampliação do faturamento das empresas do setor por meio do aumento de preços, possibilitado, primeiramente, pela política de liberalização de preços (CALIARI e RUIZ, 2013). Ainda, deve-se considerar o aumento de demanda ocasionado pelo efeito renda, que se explica pela alta elasticidade da demanda de medicamentos em relação à renda.

A estabilização apresentou grande importância ao apresentar a possibilidade de planejamento no longo prazo, que acabou por promover a retomada de investimentos da indústria farmacêutica, ao mesmo tempo em que se estabelecia a expectativa de uma nova lei de patentes, que ocorreria poucos anos mais tarde.

\subsection{Propriedade intelectual e a lei de patentes}

A patente constitui um mecanismo de apropriação muito utilizado pela indústria farmacêutica, de forma a impedir a cópia não autorizada de fármacos e medicamentos (TACHINARDI, 1993). E, no âmbito de negociações comerciais multilaterais, destaca-se o Acordo sobre Aspectos dos Direitos de Propriedade Intelectual relacionados ao Comércio, estabelecido no ano de 1994, conhecido como Acordo TRIPS, originalmente "Trade Related Aspects of Intellectual Property Rights”, considerado uma das convenções que formam a composição básica da OMC.

O Acordo TRIPS, que entrou em vigor em 1995, foi responsável por determinar padrões de proteção à propriedade intelectual para todos os países membros da OMC, de forma que as suas legislações deveriam atender aos critérios estabe- 
lecidos pelo Acordo (LEMOS, 2008). Além disso, estabeleceu a associação entre a propriedade intelectual e o comércio internacional, dois espaços associados pela globalização, que foram tratados de forma isolada por longo tempo.

Em consonância com os parâmetros da TRIPS foi sancionada no Brasil a Lei de Propriedade Industrial, $\mathrm{n}^{\circ}$ 9.279, de 14 de maio de 1996, também denominada Lei das Patentes, que se constituiu com a finalidade de estabelecer novas regras para as patentes (MATIAS-PEREIRA, 2003; SILVA, 2008).

O Acordo TRIPS foi responsável por modificar o cenário referente à cobertura dos direitos de patente, com a ampliação dos objetos patenteáveis para a área da saúde, e por consequência, para o setor farmacêutico. A lei assegura a validade da patente de medicamentos e possui o limite de vinte anos, além de estabelecer o cumprimento das condições de novidade, atividade inventiva e aplicação industrial (SILVA, 2008).

Ainda no âmbito farmacêutico, existe um componente prejudicial à efetividade do Acordo TRIPS, conhecido como TRIPS-Plus, acordos estabelecidos fora do domínio OMC, e que são responsáveis por aumentar a proteção da propriedade intelectual, de forma a inibir o acesso a medicamentos nos países membros do acordo. No entanto, esses países devem assegurar o acesso a medicamentos internamente, ainda que sejam participantes de qualquer outra convenção (PIOVESAN; CARVALHO, 2008).

Nesse sentido, uma questão pertinente se traduz no possível equilíbrio entre direito ao acesso a medicamentos e incentivo à inovação por meio da proteção patentária. Do ponto de vista da saúde pública, se torna essencial a capacitação de recursos humanos a fim de estabelecer acordos e negociações que não restrinjam esse acesso e, ao mesmo tempo, que possibilitem o desenvolvimento inovativo do setor no país (CHAVES et al, 2007).

É nesse contexto que se torna importante analisar a acessibilidade aos produtos farmacêuticos, de modo mais específico no mercado das cópias das inovações, em particular, o mercado de medicamentos genéricos (CALDEIRA, 2010).

\subsection{Medicamentos genéricos}

As discussões sobre os medicamentos genéricos iniciaram-se na década de 1970. Contudo, o primeiro passo legal rumo à Política de Medicamentos Genéricos foi a promulgação do Decreto $n^{\circ} 793 / 1993$, inserido no âmbito do Programa de Assistência Farmacêutica, elaborado pelo Ministério da Saúde.

Essa normatização foi responsável por evidenciar a denominação genérica dos medicamentos e também a prescrição por essa denominação, apesar das várias dificuldades enfrentadas para sua efetiva implementação, com destaque para as numerosas ações na Justiça, as coações por parte de figuras diplomáticas, a debilidade do sistema nacional de vigilância sanitária e a falta de ações do governo para difundir esse tipo de medicamento (BERMUDEZ, 1994).

Subsequente a esses acontecimentos, cabe destacar que para a entrada e consolidação dos medicamentos genéricos no Brasil foi necessária a discussão e a publicação da 
Política Nacional de Medicamentos do Ministério da Saúde em 1998, que está inserida na responsabilidade do Estado em formular e executar políticas econômicas e sociais que visem, entre outros, estabelecer condições que assegurem acesso universal às ações e serviços para promoção, proteção e recuperação da saúde (CALDEIRA, 2010).

A alteração mais profunda na dinâmica do setor farmacêutico no país que se segue a partir desse contexto ocorre com a publicação da Lei ${ }^{\circ} 9.787$, de 10 de janeiro de 1999, conhecida como Lei dos Genéricos, cuja elaboração teve como objetivo básico proporcionar à população o acesso a medicamentos com preços baixos e eficácia garantida (VALENTIM, 2003).

A partir da implementação da Lei dos Genéricos, o mercado farmacêutico nacional passou a apresentar três tipos de segmentos, a saber, medicamentos de referência protegidos por patentes e comercializados sob uma marca, medicamentos similares e, ainda, outro segmento de medicamentos comercializados conforme a denominação genérica. Assim, o país detinha um mercado com estrutura semelhante à de outros países (HASENCLEVER, 2004).

Nesse contexto, a dinâmica de comercialização dos medicamentos genéricos permitiu uma mudança estrutural no mercado de medicamentos, possibilitando o aumento da concorrência e a redução dos preços.

Embora essa política tenha tido como foco principal a minimização de preço, não há dúvidas de que a Lei de Medicamentos Genéricos causou uma mudança estrutural da indústria farmacêutica brasileira. A instituição dos medicamentos genéricos no mercado nacional acarretou uma transformação significativa da indústria em favor das empresas domésticas (CALIARI; MAZZOLENI; PÓVOA, 2013).

Conforme apontado pelos autores:

“...national firms had problems competing with foreign ones, mainly in innovation: the production scale did not allow national firms to create enough innovative scale to enter in more sophisticated markets. So, given the previous specialization in standardized products, the generic drugs law opened a comparative advantage guaranteed by law in favor of these firms" (CALIARI; MAZZOLENI; PÓVOA, 2013, p. 42).

A eficácia da política, portanto, também pode ser comprovada nesse sentido. Ao promover a redução dos preços dos medicamentos, outro efeito foi o aumento da participação de mercado das firmas nacionais, que passaram a integrar o cenário composto pelas grandes empresas do setor farmacêutico do país (RUIZ, et al., 2011).

Segundo Caliari e Ruiz (2013), em 1998 apenas a empresa Aché detinha capital nacional e aparecia entre as maiores do setor. Em 2005, entre as dez maiores empresas, cinco possuíam participação de capital nacional: Aché, EMS Sigma Pharma, Medley, Eurofarma e Schering do Brasil, sendo as quatro primeiras produtoras de medicamentos genéricos. É possível perceber que o aumento de participação das firmas nacionais por meio da produção de genéricos é conduzido em consonância com o aumento da participação dos genéricos na oferta total nacional (CALIARI; RUIZ; OLIVEIRA, 
2009). Em 2014, das 10 maiores empresas farmacêuticas no mercado nacional, 5 eram nacionais produtoras de medicamentos genéricos. Segundo o site Pró-genéricos, $88 \%$ da oferta de genéricos no mercado nacional no ano de 2008 advinham de empresas de capital brasileiro. Atualmente, no mercado de genéricos, por origem de capital, cerca de $90 \%$ são nacionais, $6,3 \%$ indianas, $0,8 \%$ alemãs, $0,5 \%$ espanholas e $0,6 \%$ canadenses, ou seja, o capital nacional ainda mostra crescimento desde 2008 (Pró-Genéricos, 2014).

O crescimento das firmas nacionais provocou uma redução da participação das firmas estrangeiras nesses segmentos e, ao mesmo tempo, possibilitou uma perspectiva positiva em relação à concorrência por meio de produtos de maior conteúdo tecnológico (RUIZ et al., 2011).

De acordo com os autores:

essa expansão permitiu às empresas nacionais uma escala de produção, um escopo de produtos e a constituição de uma rede de distribuição que as torna potenciais entrantes no segmento de especialidades farmacêuticas e, no limite, no segmento de produtos patenteados (RUIZ et al., 2011, p. 1057).

Para reforçar essa avaliação, de forma conclusiva, Isse (2011) destaca que a Lei dos Genéricos alcançou seu principal objetivo ao promover o acesso da população a medicamentos de qualidade a preços baixos e, por consequência, proporcionou o crescimento e a consolidação da indústria nacional, permitindo que as empresas locais alcançassem um estágio de desenvolvimento avançado comparado ao período anterior.

\subsection{Regulação e criação da agência nacional de vigilância sanitária}

No Brasil, a discussão acerca da garantia de acesso aos medicamentos para a população, que envolve diretamente o setor industrial farmacêutico, foi fortemente influenciada pela teoria da regulação econômica. Essa teoria justifica a adoção de políticas públicas regulatórias pelas falhas e ineficiências de mercado existentes, ou seja, pelas condições que levam a concorrência a não funcionar de modo adequado e eficaz. Assim, a regulação age de modo a assegurar uma alocação mais eficiente de recursos (CALDEIRA, 2010; SILVA, 2003).

Nesse contexto, a indústria farmacêutica apresenta-se como um setor da economia que apresenta diversas falhas de mercado, com destaque para a estrutura de mercado concentrada, oligopolista e, com forte presença de barreiras à entrada, decorrente do direito de patentes, dos altos investimentos em P\&D, do controle do fornecimento de fármacos, das renomadas marcas de empresas líderes, da regulamentação sanitária e técnica e das regras de dispensação do medicamento (CALDEIRA, 2010; CAPANEMA; PALMEIRA FILHO, 2004).

Demais falhas são possíveis do lado da demanda, como a existência de riscos e incerteza, dado que o estado de saúde é imprevisível, impossibilitando o planejamento de consumo de medicamentos. Além disso, identifica-se a assimetria de in- 
formação, uma vez que a informação completa sobre os medicamentos é controlada pelos laboratórios que desenvolvem os produtos, que por sua vez são capazes de influenciar os consumidores por meio de propaganda e da publicação de informações que sejam convenientes à indústria (CALDEIRA, 2010).

Diante dessas características, é possível observar que o mercado farmacêutico funciona, em sua maior parte, submetido a regulamentações por parte do governo. Os mecanismos de regulação nesse setor são capazes de influenciar tanto os produtores e vendedores quanto os consumidores (GODOY; OLIVEIRA; CÂMARA, 2004).

Conforme Andrade (2005), a regulação da oferta de medicamentos, como o controle de preços e lucros, apoio financeiro e punições, tem a finalidade de adequar a conduta da indústria farmacêutica. Já pela via da demanda, a regulação tem como intuito atuar sobre o comportamento dos consumidores, por meio do controle de prescrições, definição de tetos orçamentários, incentivo aos medicamentos genéricos, entre os principais.

De modo geral, os instrumentos de regulação farmacêutica pelo governo apresentam fundamentalmente critérios sanitários e econômicos. Enquanto a os critérios econômicos estão ligados às falhas de mercado, a regulação por fundamentos sanitários tem o objetivo básico de garantir a qualidade e segurança dos medicamentos comercializados (GODOY; OLIVEIRA; CÂMARA, 2004). Esses mecanismos podem ser visualizados na Tabela 1.

Tabela 1: Mecanismos de regulação farmacêutica pelo Estado

\begin{tabular}{l|l}
\hline \multicolumn{1}{c|}{ Metas } & \multicolumn{1}{c}{ Meios } \\
\hline A - Considerações de ordem sanitária & $\begin{array}{l}\text { Serviços de controle da qualidade dos } \\
\text { medicamentos }\end{array}$ \\
\hline $\begin{array}{l}\text { 1) Controle do número de medicamen- } \\
\text { tos no Mercado }\end{array}$ & $\begin{array}{l}\text { Farmacopéia nacional, listas de medicamentos } \\
\text { essenciais, formulários }\end{array}$ \\
\hline $\begin{array}{l}\text { 2) Controle da eficiência e da segurança } \\
\text { de medicamentos }\end{array}$ & Regulamentação de aprovação e registro \\
\hline $\begin{array}{l}\text { 3) Controle das atividades de marketing } \\
\text { das empresas farmacêuticas }\end{array}$ & Regulamentação da propaganda e promoção \\
\hline 4) Controle da distribuição & Classificação dos produtos em éticos/não éticos \\
\hline B - Considerações de ordem econômica & Serviços de controle de custo de medicamentos \\
\hline $\begin{array}{l}\text { 5) Redução dos gastos públicos com } \\
\text { medicamentos }\end{array}$ & $\begin{array}{l}\text { Regulamentação do preço e estímulo à prescrição } \\
\text { de medicamentos genéricos }\end{array}$ \\
\hline $\begin{array}{l}\text { 6) Fortalecimento da própria indústria } \\
\text { do país }\end{array}$ & $\begin{array}{l}\text { Subsídios e incentivos à indústria, controle de } \\
\text { importações, sistema de patentes }\end{array}$ \\
\hline
\end{tabular}

Fonte: Pinheiro (1999) apud Godoy; Oliveira; Câmara (2004) 
O sistema de regulação atual, que ocorre por meio de agências reguladoras, surgiu apenas na década de 1990. Apesar da presença da regulação em anos anteriores, a proposta de criação dessas agências surgiu no ano de 1996 (RAMALHO, 2011; TAVEIRA, 2013).

\subsubsection{Agência Nacional de Vigilância Sanitária (Anvisa)}

A regulação do setor farmacêutico brasileiro foi amplamente influenciada pela criação da Agência Nacional de Vigilância Sanitária (Anvisa) pela Lei n ${ }^{\circ}$ 9.782, de 26 de janeiro de 1999, regulamentada pelo Decreto $n^{\circ} 3.029$ de 16 de abril de 1999 (TAVEIRA, 2013).

A Anvisa age em todos os setores relacionados a produtos e serviços que possam afetar a saúde da população brasileira e se apresenta como uma autarquia sob regime especial, ou seja, uma agência reguladora independente tanto financeiramente quanto à sua administração, além de apresentar estabilidade de seus gestores durante o tempo de mandato. Na estrutura da administração pública federal, a Anvisa encontra-se vinculada ao Ministério da Saúde e integra o Sistema Único de Saúde (SUS), assimilando seus princípios e diretrizes (BRASIL, 2014a).

Sua responsabilidade é tanto a regulação sanitária quanto a regulação econômica. Ao mesmo tempo em que se responsabiliza por garantir a eficácia, segurança e qualidade dos medicamentos, bem como seu acesso pela população, deve estimular a competitividade para a indústria e promover a política de genéricos (HASENCLEVER et al., 2002; BRASIL, 2014a).

Segundo Taveira (2013), o setor farmacêutico se constitui em um dos principais segmentos de ação por parte da Anvisa, especialmente no que se refere aos seus mecanismos de regulação sanitária. Além de sua competência regulatória, a Anvisa ainda é responsável por coordenar o Sistema Nacional de Vigilância Sanitária (SNVS), de modo integrado com outros aparelhos públicos ligados à área da saúde e, atuar como Secretaria Executiva da Câmara de Regulação do Mercado de Medicamentos (CMED) (BRASIL, 2014b)

Cabe, nesse contexto, ressaltar a criação da Câmara de Regulação do Mercado de Medicamentos (CMED), em 2003, como um órgão interministerial responsável por regular o mercado e estipular formas de fixação e adequação de preços de medicamentos. Esse órgão regulador é derivado da Câmara de Medicamentos (CAMED), instituída em dezembro de 2000, como forma de retomar o controle dos preços dos medicamentos (BRASIL, 2014b; CALDEIRA, 2010).

\section{Políticas Industriais pós - 2003}

Os anos 1990 assistiram ao uso restrito de políticas industriais ativas frente ao cenário macroeconômico de abertura da economia e a disposição do país ao novo cenário liberal. Apesar disso, resultados favoráveis, como a contenção da queda da 
produtividade do trabalho e a modernização industrial por meio de novas técnicas gerenciais, que por sua vez, permitiram uma combinação mais eficiente de fatores e insumos na produção, puderam ser verificados (NASSIF, 2003).

No entanto, mesmo frente a esses fatores positivos, não houve modificação na capacidade competitiva da indústria nacional, que continuou a possuir uma posição frágil no cenário externo. Diante disso, o país não foi capaz de absorver vantagens comparativas naquelas indústrias dinâmicas produtoras de bens de alto valor agregado frente ao mercado internacional, adequadas a sustentar um crescimento no longo prazo (NASSIF, 2003).

Nessa conjuntura, o início dos anos 2000 apresentava a necessidade de resgate de políticas industriais concretas que se conformassem com uma política de desenvolvimento nacional, de forma a considerar as particularidades do Brasil (CANO; SILVA, 2010). A década passada compreendeu um conjunto de políticas do Governo Federal indicando a importância do setor saúde no contexto do desenvolvimento industrial do país. Foram lançadas as seguintes políticas industriais: Política Industrial, Tecnológica e de Comércio Exterior (PITCE); Política de Desenvolvimento Produtivo (PDP) e o Plano Brasil Maior (PBM). Além de outros setores, tais políticas serviram de incentivo, especialmente, à Indústria Farmacêutica.

\subsection{Política Industrial, Tecnológica e de Comércio Exterior (PITCE)}

No início de 2003, o Ministério do Desenvolvimento, Indústria e Comércio Exterior (MDIC) estabeleceu o Fórum de Competitividade da Cadeia Produtiva Farmacêutica com a responsabilidade de desenvolvimento produtivo da cadeia de fármacos e medicamentos, além de promover o acesso da população a medicamentos oferecidos pelo governo (CAPANEMA, 2006).

O Fórum foi responsável por tratar das políticas públicas referentes ao setor farmacêutico e, para isso, possuía uma organização composta por diversos participantes, a saber, o MDIC, o Ministério da Saúde, representantes de ministérios, a Anvisa, o órgão financiador Banco Nacional de Desenvolvimento Econômico e Social (BNDES), o Instituto Nacional de Propriedade Industrial (INPI), além de sindicatos (CAPANEMA, 2006).

Em continuidade a esse processo, ainda em novembro de 2003 foi lançada a Política Industrial, Tecnológica e de Comércio Exterior (PITCE), que envolvia setores como bens de capital, softwares e semicondutores, além dos fármacos e medicamentos, ou seja, setores que demandavam altos investimentos em $\mathrm{P} \& \mathrm{D}$, constituindo uma política na ótica da competência inovativa (RUIZ et al., 2011).

A condução dessa política considerava importante a articulação paralela entre o estímulo à eficiência produtiva, o comércio internacional, a inovação e a capacitação tecnológica, como sendo determinante para a indústria nacional (CAPANEMA, 2006). No que diz respeito à indústria farmacêutica, a política e seus planos de ação demonstravam estímulo e suporte às instituições nacionais de $\mathrm{P} \& \mathrm{D}$, pro- 
moção da capacidade produtiva de medicamentos no país, além da consolidação do sistema de propriedade intelectual e do fortalecimento da cooperação entre instituições públicas e privadas nas atividades de pesquisa (RUIZ et al., 2011).

Essa política se manteve em atividade até ser lançada pelo governo uma nova política industrial que pretendia maior abrangência e densidade em relação à PITCE, denominada Política de Desenvolvimento Produtivo (PDP) (CANO; SILVA, 2010).

\subsection{A Política de Desenvolvimento Produtivo (PDP)}

A Política de Desenvolvimento Produtivo (PDP) foi lançada em 12 de maio de 2008 , com o objetivo de promover a capacidade competitiva da economia nacional e sua sustentação no longo prazo, de forma a integrar os mecanismos de políticas públicas disponíveis, fortalecer o arranjo institucional do governo e intensificar a relação com o setor privado (BRASIL, 2014c).

Nesse sentido, a PDP, como uma continuidade da PITCE, pretendia maior amplitude, densidade e articulação em relação às medidas anteriores. Buscava-se maior transparência em relação às metas e ampliação dos setores incentivados e dos mecanismos de apoio, principalmente nas áreas carentes de inovação e tecnologia. Além disso, o fortalecimento das pequenas empresas constituía outro foco da política (BRASIL, 2014c).

As ações propostas pela PDP compreendem três categorias: Ações Sistêmicas, Destaques Estratégicos e Programas Estruturantes, de modo a conceder aportes financeiros e incentivos fiscais de acordo com cada área do complexo industrial brasileiro.

O Complexo Industrial da Saúde está inserido no nível de Programas Estruturantes, que compreende os setores industriais estratégicos, pelo motivo de ser um setor em que a competitividade está ligada ao desenvolvimento científico e tecnológico para promover atividades da inovação. Nesse sentido, houve uma sequência e aprofundamento das ações da PITCE para o setor, porém com maior intervenção pública (RUIZ, et al., 2011).

Desse modo, a PDP estabeleceu alguns objetivos para o setor da saúde, como investir de forma mais intensa em inovação, elevar e variar as exportações; consolidar as firmas nacionais e os laboratórios públicos, promovendo sua modernização, além de trazer para o país a produção e centros de $\mathrm{P} \& \mathrm{D}$ de empresas internacionais com alto grau de desenvolvimento tecnológico (CALDEIRA, 2010).

As iniciativas do programa para o setor industrial da saúde ainda compreenderam uma série de ações, guiadas para atingir os objetivos propostos. São elas: uso do poder de compra do Estado para estimular a capacidade produtiva; desenvolvimento de mecanismos de financiamento para conformação da cadeia produtiva; aumento dos benefícios para $\mathrm{P} \& \mathrm{D}$; constituição de cadeias de cooperação ao desenvolvimento tecnológico e industrial; e desenvolvimento da regulação necessária para a condução das ações previstas na política (RUIZ, et al., 2011). 
A PDP seguiu as principais condutas da PITCE, porém passou a considerar a heterogeneidade industrial do Brasil no estabelecimento dos setores emergentes. Ainda assim, o setor da saúde destacou-se como uma área estratégica a ser desenvolvida devido ao seu elevado potencial de difusão do conhecimento e inovação (SILVA, 2014).

Ainda que não seja possível avaliar profundamente os resultados, visto que se trata de uma política de longo prazo, as metas estipuladas pela PDP possuem uma perspectiva positiva, especialmente, para o setor da saúde (BRANDÃO; DRUMMOND, 2012).

\subsection{O Plano Brasil Maior (PBM)}

O Plano Brasil Maior foi implantado em agosto de 2011, durante o primeiro ano do governo de Dilma Rousseff, se constituindo como a mais recente política industrial do Governo Federal. A política apresentou bastante similaridade com a política industrial anterior, seguindo a mesma orientação em relação às iniciativas para promover o desenvolvimento de inovação e tecnologia, importantes para o setor industrial farmacêutico (SOARES; CORONEL; MARION FILHO, 2013).

Dentre as diretrizes compreendidas na sua dimensão setorial, o PBM tem como referência o fortalecimento das cadeias produtivas e ações para promover a ampliação e criação de novos conhecimentos científicos e tecnológicos e sua inserção nas empresas (BRASIL, 2014d).

Nesse sentido, o Complexo Industrial da Saúde é evidenciado como um setor relevante, de forma que para incentivar o desenvolvimento de sua cadeia produtiva e estimular a capacitação tecnológica, o governo passou a atuar como consumidor de fármacos e medicamentos produzidos no país que incorporem inovação. Essas compras consistem em um importante instrumento de crescimento para o setor farmacêutico (SILVA, 2014).

Entre outras ações, foi criado o Programa Inova Empresa, a fim de fomentar a produção e a concorrência por meio do aumento dos investimentos em inovação em áreas estratégicas, dentre elas, o complexo da saúde, recebendo grandes aportes financeiros. Os agentes financiadores do programa são a Financiadora de Estudos e Projetos (FINEP), e o Banco Nacional Desenvolvimento Econômico e Social (BNDES) (BRASIL, 2014d).

É possível depreender que o PBM é um plano amplo e sistematizado, de forma a continuar com os planos anteriores, porém de um modo mais avançado. Com dificuldades e características positivas, como seus predecessores, ainda não é possível analisar profundamente seus resultados, visto que a data limite estabelecida para o alcance dos objetivos propostos é o ano de 2014. 


\subsection{Principais ações das políticas industriais pós-2003}

Todas as políticas industriais explicitadas anteriormente, resguardadas suas particularidades, apresentam a característica comum de propor objetivos e instrumentos de ação que enfatizam a importância do Complexo Industrial da Saúde no contexto de desenvolvimento do país em relação ao seu potencial produtivo, inovativo e social. A seguir são apresentadas algumas ações abarcadas nessas políticas, que foram responsáveis por influenciar a indústria farmacêutica nacional (CALIARI; RAPINI, 2014).

\subsubsection{Profarma}

Dentre as ações previstas na PITCE para o setor farmacêutico, destaca-se o Programa de Apoio ao Desenvolvimento da Cadeia Produtiva Farmacêutica (Profarma), instituído em 2004. O programa teve suas atividades financiadas pelo BNDES devido às necessidades de investimento do setor farmacêutico, de modo a oferecer aporte financeiro às atividades de produção, pesquisa, desenvolvimento e inovação, propiciando a consolidação e incentivando o progresso da indústria local (PALMEIRA FILHO; CAPANEMA, 2010).

Com relação a alguns resultados parciais do Profarma, Pieroni, Pereira e Machado (2011) apontam resultados positivos no apoio à modernização, expansão e adequação do processo produtivo das empresas farmacêuticas. Já em relação ao investimento em inovação, o Profarma apresentou efeitos limitados no estímulo a atividades mais inovadoras na indústria.

Entre o ano de sua criação, 2004, e o ano de 2007, 49 projetos foram financiados pelo Profarma, totalizando um montante de R $\$ 2$ bilhões em investimento, sendo que $49 \%$ foram empregados na promoção da capacidade produtiva da indústria, $12 \%$ nos projetos de $\mathrm{P} \& \mathrm{D}$ e $39 \%$ na reestruturação financeira de empresas locais. No ano 2007, o BNDES disponibilizou recursos da ordem de R 3 bilhões (CALIARI; RAPINI, 2014).

Até o ano de 2012 estima-se que o BNDES tenha financiado projetos da ordem de R 912 milhões, porém, mudando a direção dos investimentos em relação ao período anterior, de modo que $49 \%$ dos projetos eram atuantes em atividades de P\&D, 40\% dos projetos são voltados à estrutura industrial e $11 \%$ dos projetos são destinados à exportação (CALIARI; RAPINI, 2014).

Em 2013, ainda por meio do Profarma foi reafirmado o apoio ao desenvolvimento do complexo industrial da saúde, enfatizando a manutenção de ações promotoras de $\mathrm{P} \& \mathrm{D}$ e de inovação no setor. Além disso, foi criado um novo subprograma denominado Profarma - Biotecnologia, com o intuito de fomentar o desenvolvimento de biotecnológicos. 


\subsubsection{Lei da Inovação e Lei do Bem}

De forma específica no âmbito de inovação, a PITCE se apresentava como uma política industrial que fosse capaz de sustentar o crescimento de longo prazo por meio da inovação, por intermédio da incorporação de tecnologia aos produtos nacionais, aumentando seu valor agregado e, por conseguinte, as exportações do país.

Nesse sentido, há dois marcos legais importantes referentes à inovação, derivados da PITCE, a saber: a Lei da Inovação (Lei 10.973, de 02/12/04) e a Lei do Bem (Lei 11.196, de 21/11/05).

A Lei da Inovação foi regulamentada em 11 de outubro de 2005 pelo Decreto 5.563 a fim de incentivar as parcerias entre empresas, universidades e centros de pesquisa e tecnologia, de forma a criar um ambiente propício e facilitado para a criação de inovações científicas e tecnológicas e, consequentemente, fomentar a competitividade das firmas nacionais (MOREIRA et al. 2007).

Já o segundo marco legal, conhecido como Lei do Bem, foi regulamentado pelo decreto $\mathrm{n}^{\circ} .5 .798$, de 7 de junho de 2006 e define os incentivos fiscais para as empresas que investem em P\&D em inovação e tecnologia. Os benefícios determinados por essa lei são imediatos, de forma que não é necessária a submissão de projetos para serem autorizados, bastando apenas declarar os gastos em P\&D à Receita Federal (Ruiz et al, 2011).

Uma crítica a essa lei se constitui no prejuízo à pequena empresa, uma vez que a declaração do imposto de renda é feita sobre o lucro. Dessa forma, somente as empresas que adotam o sistema de lucro real são beneficiadas, enquanto as pequenas e médias empresas que, normalmente, optam pelo sistema Simples de declaração, não recebem incentivos dessa natureza (RUIZ et al., 2011).

\subsubsection{Financiamentos para Inovação e P\&D}

Os financiamentos para atividades inovativas envolvem um alto nível de incerteza e risco em relação ao processo de $\mathrm{P} \& \mathrm{D}$, o que faz com que os recursos disponibilizados pelo setor privado sejam reduzidos e os requisitos para a obtenção de empréstimos sejam elevados. Nesse contexto, as possibilidades de investimento das empresas se restringem a recursos próprios ou financiamentos públicos (CALIARI; RAPINI, 2014).

Os financiamentos públicos direcionados às atividades de inovação são disponibilizados, em sua maioria, pela Financiadora de Estudos e Projetos (FINEP), Conselho Nacional de Desenvolvimento Científico e Tecnológico (CNPq), do BNDES e das Fundações de Assistência à Pesquisa Estaduais (FAPs) (CALIARI; RAPINI, 2014).

O BNDES garante investimentos em áreas que beneficiam a infraestrutura das empresas e, por conseguinte, permite um maior financiamento via recursos próprios nas inovações. Já a FINEP tem como foco o estímulo à capacitação científica 
e tecnológica no setor industrial, universidades e centros de pesquisa, por meio de Fundos Setoriais de financiamento. Quanto às universidades e institutos de ciência e tecnologia, existe um alto nível de dependência das FAPs devido à ausência da possibilidade de autofinanciamento (CALIARI; RAPINI, 2014).

\subsubsection{O Uso do Poder de Compra do Estado}

A partir do PBM houve a ampliação do uso do Poder de Compra do Estado no setor farmacêutico (GADELHA; COSTA, 2012).

A utilização desse instrumento tem o intuito de assegurar a demanda pelos produtos, ainda que exista um diferencial de preço positivo no curto prazo. Assim, esse subsídio colabora com o desenvolvimento de novos processos e produtos por parte das empresas nacionais. Além disso, estimula a competitividade dessas empresas no longo prazo (CALIARI; RAPINI, 2014).

Nesse sentido, algumas ações efetivas foram implementadas, como a instituição da Lei 12.349, de 2010, que passa a considerar uma margem de preferência para produtos e serviços que sejam de desenvolvimento e inovação tecnológica realizados no país, em um valor de $25 \%$ sobre o preço dos produtos e serviços estrangeiros (CALIARI; RAPINI, 2014).

Já em 2012, foram definidas novas especificações para a indústria farmacêutica por meio do Decreto 7.713, de 2012. Essa legislação estabelece a aplicação de margem de preferência nas licitações realizadas no âmbito da Administração Pública Federal para aquisição de fármacos e medicamentos, com valores diferenciados: produtos que utilizam insumos produzidos no Brasil e que são resultado de inovações tecnológicas dentro do país tem margem de preferência de $20 \%$; produtos nacionais que utilizam insumos estrangeiros possuem margem de preferência de $8 \%$ (CALIARI; RAPINI, 2014).

Ainda, deve-se destacar a alteração da Lei $n^{\circ} 8.666$ pela Lei $n^{\circ} 12.715$, que em seu artigo 73 passa a desobrigar a licitação nos contratos em que existir transferência de tecnologia de produtos estratégicos para o Sistema Único de Saúde (SUS), até mesmo na aquisição destes produtos durante as etapas de assimilação tecnológica (BRASIL, 2014e).

Da mesma forma, libera os órgãos ou entidades que produzem produtos estratégicos para o SUS do limite temporal antes estabelecido para sua criação, em que era permitida a criação somente em data anterior a vigência da lei no 8.666 (BRASIL, 2014e).

\subsubsection{Grupo Executivo do Complexo Industrial da Saúde (GECIS)}

Todas as orientações mais recentes acerca das políticas de apoio ao desenvolvimento da indústria farmacêutica, bem como do complexo industrial da saúde como um todo, foram estabelecidas e conduzidas pelo Grupo Executivo do Complexo Industrial da Saúde (GECIS) (VARGAS; BURD, 2012). 
O GECIS foi criado por decreto presidencial em 12 de maio de 2008, vinculado ao Ministério da Saúde. O grupo tem como objetivo a promoção de medidas e ações para efetivação do marco regulatório referente à estratégia de desenvolvimento do Governo Federal para a área da saúde, de acordo com as orientações das políticas nacionais de fortalecimento do complexo produtivo e de inovação em saúde (BRASIL, 2014).

De modo geral, o Grupo é responsável pelas decisões e discussões acerca da condução políticas industriais e de inovação para Sistema de Inovação de Saúde (CALIARI; RAPINI, 2014).

\subsubsection{Parceria Público-Privada (PPP) e Parceria do Desenvolvimento Produtivo (PDP)}

A formação das parcerias público-privadas (PPP's) surgiu a partir do intuito governamental de melhorar a eficiência no serviço público, por meio da Lei Federal 11.079/04. De modo mais específico, foram institucionalizadas a partir de 2008, por meio da Portaria 978, inclusas no Sistema de Inovação em Saúde (CALIARI; RAPINI, 2014).

Com essa lei surgiu o modelo de concessão administrativa, utilizada no setor da saúde, em que o Estado é usuário de um serviço, ao mesmo tempo em que é responsável pelo pagamento do parceiro privado. Ao colaborar com o processo produtivo dos laboratórios públicos, as empresas privadas têm participação nos lucros das vendas realizadas ao Estado. Esta última é a mais utilizada no setor da saúde, a fim de viabilizar investimentos em infraestrutura, serviços e áreas com limitações orçamentárias, além de buscar a melhoria da qualidade do serviço público de saúde e ofertá-lo de forma mais eficiente (CALIARI; RAPINI, 2014).

As parcerias do Desenvolvimento Produtivo (PDP), de forma mais recente, foram estabelecidas a partir da Portaria 837, de 2012. Do mesmo modo que as PPP's, esse tipo de parceria estabelece o relacionamento entre as esferas pública e privada na produção de medicamentos. A diferença se traduz na obrigação de transferência de tecnologia do setor privado para os laboratórios públicos (CALIARI; RAPINI, 2014).

Esse tipo de parceria, além da diminuição dos custos originada pelo licenciamento do produto, permite a capacitação tecnológica pelo conhecimento garantido pela transferência tecnológica. Além de assegurar um ambiente sustentado pelos recursos no curto prazo, garante melhores perspectivas para o desenvolvimento do setor no longo prazo (CALIARI; RAPINI, 2014).

No ano de 2013 foram estabelecidos 104 parcerias para a produção de 97 produtos em Saúde no Brasil, abrangendo 19 laboratórios públicos e 60 privados, de modo a economizar de R\$ 4,1 bilhões ao ano (CALIARI; RAPINI, 2014). 


\subsubsection{Revisão do Marco de Acesso à Biodiversidade}

O Brasil detém a maior parte da biodiversidade mundial, de modo a apresentar um grande potencial na criação de princípios ativos no setor de fármacos e medicamentos para a indústria farmacêutica. No entanto, o acesso aos recursos naturais disponíveis se encontrava limitado por um marco legal de acesso a biodiversidade, criado como forma de proteção ao uso ilegal desses recursos (IPDFARMA, 2014; ETHOS, 2014). Essa barreira surge por meio da regulação do acesso ao patrimônio genético, ou seja, por intermédio do controle das atividades de pesquisa, desenvolvimento e inovação derivadas da biodiversidade brasileira, bem como da distribuição dos benefícios decorrentes de seu uso, que só pode ser efetivado por meio de autorização do Estado (AZEVEDO, 2005; SACCARO JR., 2011).

Pelo fato de consistir em uma medida provisória, sem uma análise profunda da questão, essa regulamentação resultou em contrariedades por parte de todos os agentes envolvidos. A principal desaprovação partiu da comunidade acadêmica, uma vez que esse marco cria regras muito rígidas e entraves burocráticos ao acesso ao patrimônio genético para os pesquisadores, de forma a prejudicar o progresso científico local e, até mesmo a própria distribuição de benefícios, visto que eles não chegam a ser produzidos (IPDFARMA, 2014; CLEMENT, 2007).

Nesse sentido, houve uma discussão para revisão da Medida Provisória $\mathrm{n}^{\circ}$ 2.186-16, de 2001. A revisão desse marco legal teve o intuito de assegurar juridicamente as atividades de pesquisa e inovação feitas a partir da biodiversidade brasileira e solucionar as dificuldades relativas ao acesso aos recursos naturais, enfrentadas pela indústria farmacêutica há mais de uma década (IPDFARMA, 2014).

O projeto de lei que propõe um novo marco regulatório nesse âmbito compreende uma transformação na medida anterior, de forma a beneficiar a pesquisa científica garantindo o acesso a recursos genéticos, reduzir a burocracia dos processos e promover a biotecnologia local.

\subsubsection{Ciência sem Fronteiras}

Ciências sem Fronteiras se constitui em um programa de promoção da ciência, tecnologia e inovação criado em 2011 pelo governo federal brasileiro. $O$ incentivo dessas três áreas se dá por meio do intercâmbio e da mobilidade internacional de alunos e pesquisadores disponíveis a estabelecer uma relação de conhecimento que possibilitem a competitividade e a capacitação tecnológica do país (BRASIL, 2014f).

O subsídio concedido por intermédio de bolsas de estudos busca promover algumas áreas que demandam inovação e tecnologia para o seu desenvolvimento, com destaque para os setores de biologia, ciências biomédicas e da saúde, fármacos, biodiversidade e bioprospecção (BRASIL, 2014f). 
As principais instituições promotoras do programa são o Conselho Nacional de Desenvolvimento Científico e Tecnológico (CNPq) e a Coordenação de Aperfeiçoamento de Pessoal de Nível Superior (Capes) (BRASIL, 2014f).

Uma iniciativa recente, do ano de 2013, que merece destaque se refere à parceria da Capes com a empresa farmacêutica Sanofi no domínio do Programa, de forma a possibilitar a participação de pesquisadores locais em processos essenciais à pesquisa e desenvolvimento de um fármaco, nos núcleos de pesquisa internacionais da empresa. A parceria, além de proporcionar a capacitação dos pesquisadores, oferece a possibilidade de colocação na Sanofi (BRASIL, 2014f).

Essa associação de uma grande empresa farmacêutica ao programa foi um passo importante para fomentar o conhecimento nessa área e abre caminho para outras empresas do setor farmoquímico aderirem a este modelo de cooperação que possui o potencial de difundir mais rapidamente a inovação no setor (BRASIL, 2014f).

\section{Discussão e considerações finais sobre a Indústria Farmacêutica}

A estrutura de oferta verificada na evolução histórica da indústria farmacêutica brasileira possui um viés internacional desde o começo do século XX. Essa tendência se acentuou na década de 1950 com a chegada das multinacionais e a internacionalização da indústria, tendo se mantido até a década de 1970, momento em que as firmas nacionais começaram a obter espaço no mercado doméstico por meio da decodificação dos produtos originas via engenharia reversa, facilitada pela Lei de Patentes. Essa prática, contudo, não promoveu incentivo à aprendizagem de produção e de $\mathrm{P} \& \mathrm{D}$, de forma que ainda na década de 90 as empresas nacionais se posicionavam em etapas de $\mathrm{P} \& \mathrm{D}$ de menor conteúdo tecnológico.

Os anos 1980 compreenderam tentativas de proteção à produção doméstica de fármacos e de redução da dependência da indústria farmacêutica em relação à produção de medicamentos. Porém, as necessidades macroeconômicas da década e a liberalização de importações no início da década de 90 acabaram por favorecer as empresas multinacionais e, assim, intensificar a dependência externa na oferta dentro do território nacional. Em suma, a década de 1990 representou o período de maior transformação da indústria farmacêutica nacional, alterando de forma radical seu ambiente competitivo. Essa fase foi marcada pelas políticas industriais horizontais, tendo alguns resultados como: aumento das importações, baixo crescimento das exportações, aumento significativo dos preços; aquisições de firmas nacionais por estrangeiras e estagnação da produção nacional (CALIARI; RUIZ, 2013).

Em meio a essa movimentação nociva à oferta nacional, em 1996, com a Lei das Patentes, houve o intuito de formalizar de maneira legal a instituição do poder das empresas estrangeiras. Essa lei foi conveniente às empresas multinacionais, de forma a promover um aumento do número de suas patentes e, por conseguinte, a ampliação do poder das mesmas no mercado nacional. A Lei das Patentes representou uma barreira para as empresas nacionais, sendo que essas possuíam dificuldades 
para alcançar escala suficiente na produção e inovação para entrar em um mercado dominado por multinacionais. Nesse sentido, a possibilidade de inserção em mercados menos dinâmicos se mostrou como uma viável solução para as empresas nacionais com a implantação da lei de medicamentos genéricos, em 1999.

A política de medicamentos genéricos no Brasil foi responsável pela mudança estrutural do mercado de medicamentos, bem como de todo o setor industrial farmacêutico. Esse contexto permitiu o aumento da parcela de mercado dominada por empresas locais, uma vez que conseguiram explorar as oportunidades ocasionadas pela política, adquirindo capacitação produtiva, sobretudo nas fases de formulação dos medicamentos (CALIARI e RUIZ, 2013).

Contudo, apesar da primeira movimentação das empresas nacionais, o mercado de medicamentos genéricos tem visto o incremento de oferta via entrada de empresas multinacionais. Esse cenário tem acontecido, em alguma parte, por meio da aquisição de firmas nacionais já bem instaladas, como forma de capturar suas vantagens competitivas produtivas e comerciais (VARGAS; BURD, 2012; CALIARI e RUIZ, 2013). Além disso, as empresas nacionais, ainda que tenham aumentado sua capacidade produtiva e participação no mercado nacional por meio dos genéricos, apresentam uma pequena participação no espaço de produtos tecnológicos de maior valor agregado, principalmente na área de desenvolvimento de biotecnológicos (VARGAS et al.; 2012).

Algumas iniciativas foram tomadas pelas firmas nacionais, como aumento de processos que incorporem inovação, aumento dos gastos em $\mathrm{P} \& \mathrm{D}$ e parcerias com outras empresas. No ano 2000 foi criada a Coinfar, uma joint-venture para P\&D, formada pela Biolab Sanus, União Química e Biosintética. Em 2005, foi criada a Ybios, joint-venture entre o grupo Centraflora, Natura e Orsa Florestal, com ênfase na agregação de valor à biodiversidade nacional. A Biolab e a Eurofarma constituíram a Incrementha, com foco na criação de inovações tecnológicas para novos produtos.

Mais recentemente, empresas domésticas criaram outras joint-ventures. Em particular, destacam-se a Orygen Biotecnologia S.A., controlada pelos proprietários Biolab Sanus, Cristália e Eurofarma, com a finalidade de produção de biotecnológicos, uma vez que essas firmas não possuem capacidades financeiras e tecnológicas separadamente para realizar esse tipo de produção e a Bionovis S.A., possuindo como proprietários Aché, EMS, Hypermarcas e União Química. Essa joint-venture, do mesmo modo, tem por objetivo o desenvolvimento de produtos biotecnológicos (CALIARI e RUIZ, 2013). Essas iniciativas demonstram que a capacitação tecnológica passou a fazer parte da estratégia de algumas das grandes empresas nacionais. Assim, pode-se destacar uma tendência positiva do país em relação à capacitação inovativa do setor industrial farmacêutico nos últimos dez anos. Apesar das deficiências em relação às grandes multinacionais, existe um considerável aumento dos esforços tecnológicos e de inovação para as firmas nacionais, com destaque para o aumento crescente da taxa entre P\&D e receita de vendas (PIERONI; PEREIRA; MACHADO; 2011; SANTOS; PINHO, 2012). 
Concomitantemente à capacitação produtiva privada, a década passada contemplou uma sequência de políticas do Governo Federal evidenciando o setor da saúde e, consequentemente, sinalizando a importância do desenvolvimento da capacidade tecnológica, além da produtiva, para o progresso da indústria farmacêutica no país. De formas diversas, várias ações destacadas dentro das políticas industriais promulgadas desde 2003 (primeiro a PITCE e depois a PDP e a PBM) têm sinalizado a utilização de instrumentos verticais e horizontais para promover fomento às atividades de produção, ciência e inovação na indústria farmacêutica nacional. $\mathrm{Na}$ PITCE pôde ser destacada a relevância do Financiamento via Profarma, a instituição do Grupo de Apoio ao Complexo Industrial da Saúde (GECIS) e as Leis da Inovação e Lei do Bem. A PDP intensificou essas políticas e promoveu o espaço para a utilização de parcerias público-privadas e parcerias de desenvolvimento produtivo. A PBM tem se mostrado também uma estratégia de continuidade na utilização dessas políticas, com a inclusão do uso do poder de compra do Estado, de novas capacitações científicas (como por exemplo o Programa Ciência Sem Fronteiras) e de um ambiente regulatório modificado para o uso da biodiversidade nacional.

Especificamente em relação às PDP's, essas parcerias permitem, além do benefício à capacidade produtiva de princípios ativos, a redução do tempo para promover a capacitação tecnológica e inovativa no setor farmacêutico, abrindo espaço para o desenvolvimento de medicamentos biotecnológicos no país, um dos resultados esperados das PDP's. Até o início de 2011, cinco parcerias público-privadas compreendiam a elaboração e fabricação de produtos biológicos (REIS; LANDIM, PIERONI; 2011).

A incorporação da biotecnologia e dos medicamentos biológicos pelas empresas farmacêuticas nacionais é importante no sentido de sustentar a competitividade do setor no longo prazo, especialmente pela expectativa de aumento da concorrência no mercado de genéricos, absorvido, em parte, pelas multinacionais (REIS; PIERONI; SOUZA, 2010). Nesse sentido, nos últimos anos é possível observar uma maior atenção ao mercado de medicamentos biológicos, por parte das empresas domésticas.

Em suma, a inserção na pesquisa biotecnológica se apresenta como uma janela de oportunidade para a indústria farmacêutica nacional, capaz de ser sustentada pelas firmas consolidadas no país e por instrumentos eficazes por parte do Estado (REIS, LANDIM, PIERONI; 2011; PIMENTEL et al.; 2013).

Assim, pode-se concluir que por meio da união entre políticas industriais e parcerias com empresas privadas, esse novo caminho biotecnológico pode representar uma tendência promissora, uma vez que a incorporação de capacidades tecnológicas e inovativas na produção de medicamentos, ao agregar valor aos produtos, é capaz de promover o desenvolvimento da indústria farmacêutica (REIS, LANDIM, PIERONI; 2011; PIMENTEL et al.; 2013). No sentido amplo da avaliação da evolução histórica da indústria farmacêutica realizada nesse trabalho, o momento atual parece ser o mais promissor no sentido de fomento dessas atividades. 


\section{Referências}

AZEVEDO, C. M. A. A regulamentação do acesso aos recursos genéticos e aos conhecimentos tradicionais associados no Brasil. Biota Neotropica. v.5, n.1, Campinas, 2005.

BERMUDEZ, J. Medicamentos genéricos: uma alternativa para o mercado brasileiro. Cadernos de Saúde Pública, Rio de Janeiro, v. 10, n. 3, p. 368-378, jul./set. 1994.

BRANDÃO, L. A.; DRUMMOND, C. E. I. Políticas pró-inovação: uma análise da política industrial nos oito anos do governo Lula. Revista de Economia e Tecnologia (RET), Curitiba, v. 8, n. 2, p. 143 -156, abr./jun. 2012.

BRASIL. PORTAL ANVISA. 2014a. Agência Nacional de Vigilância Sanitária. Disponível em < http://portal.anvisa.gov.br/>. Acesso em: 05/06/2014.

BRASIL. PORTAL ANVISA. 2014b. Efeitos da Resolução CMED nº 02/04 no processo de análise de preços de novos medicamentos. Disponível em: < http://portal.anvisa.gov.br> Acesso em: 01/07/2014.

BRASIL. MINISTÉRIO DO DESENVOLVIMENTO, INDÚSTRIA E COMÉRCIO EXTERIOR. 2014c. Política de Desenvolvimento Produtivo (PDP). Disponível em: < http://www.mdic.gov.br/pdp >. Acesso em 20/05/2014.

BRASIL. MINISTÉRIO DO DESENVOLVIMENTO, INDÚSTRIA E COMÉRCIO EXTERIOR. 2014d. Plano Brasil Maior. Disponível em: < www.brasilmaior.mdic.gov.br/>. Acesso em: 21/05/2014.

BRASIL. 2014e. Lei $\mathrm{n}^{\mathrm{O}} 12.715$ de setembro de 2012. Altera a lei Lei $\mathrm{n}^{\mathrm{o}} 8.666$ de 21 de junho de 1993 sobre licitações e contratos da Administração Pública.

BRASIL. CIÊNCIA SEM FRONTEIRAS. 2014f. Disponível em: <www. cienciasemfronteiras.gov.br/>. Acesso em: 04/07/2014.

CALDEIRA, T. R. Acesso ao medicamento: direito à saúde no marco da regulação do mercado farmacêutico. 2010. 179 f. Dissertação (Mestrado em Política Social) - Departamento de Serviço Social, Instituto de Ciências Humanas Universidade de Brasília, Brasília, 2010. 
CALIARI, T., RAPINI, M.S. (2014) A Infraestrutura Científica em Saúde. mimeo. $43 \mathrm{p}$.

CALIARI, T., MAZZOLENI, R., POVOA, L. M. C. Innovations in the Brazilian Pharmaceutical Industry in Post-TRIPS. In: MANI, S., NELSON, R. R. (Org.). Trips Compliance, National Patent Regimes and Innovation. 1ed. Northampton: Edward Elgar, 2013, v. 1, p. 10-35.

CALIARI, T., RUIZ, R. M. Brazilian pharmaceutical industry and generic drugs policy: Impacts on structure and innovation and recent developments. Science E Public Policy (Print), v. 1, p. 1-12, 2013.

CALIARI, T.; RUIZ, R. M.; OLIVEIRA, A. M. H. C. Uma Década De Medicamentos Genéricos: Sucesso Relativo E Progressiva Perda De Eficiência? In: XXXVII Encontro Nacional de Economia, 2009, Foz do Iguaçu.

CANO, W.; SILVA, A. L. G. Política industrial do governo Lula. Campinas: IE/UNICAMP, 2010. (Texto para discussão, 181).

CAPANEMA, L. X. L. A indústria farmacêutica brasileira e a atuação do BNDES. BNDES Setorial, n. 23, p. 193-216, mar. 2006.

CAPANEMA, L. X. L.; PALMEIRA FILHO, P. L. "A cadeia farmacêutica e a política industrial: Uma proposta de inserção do BNDES". In: BNDES Setorial, $\mathrm{n}^{\circ}$ 19. Rio de Janeiro, março de 2004. pp. 23-48.

CASTILHO, M. Encadeamentos produtivos das atividades exportadoras na América Latina: o caso dos setores industriais no Brasil. Serie Comercio y Crecimiento Inclusivo. Working Paper, n.134. 2011.

CHAVES, G. C., OlIVEIRA, M A, HASENCLEVER, L, MELO, L. A evolução do sistema internacional de propriedade intelectual: proteção patentária para o setor farmacêutico e acesso a medicamentos. Cad. Saúde Pública, Rio de Janeiro, fev, 2007.

CLEMENT, C. R. Um pote de ouro no fim do arco-íris? O valor da biodiversidade e do conhecimento tradicional associado, e as mazelas da lei de acesso - uma visão e proposta a partir da Amazônia. Amazônia: Ciência \& Desenvolvimento, v. 3, n. 5, p. 7-28, Belém, 2007.

CRFSP - Conselho Regional de Farmácia do Estado de São Paulo. 2014. Disponível em <http://portal.crfsp.org.br/historia-da-farmacia-/294-seculo-xx.html>. Aces- 
so em: $16 / 01 / 2014$.

ETHOS. Instituto Ethos de Empresas e Responsabilidade social. Disponível em: <http://www3.ethos.org.br> Acesso em: 04/07/2014.

FERST, G. C., Análise da Indústria Farmacêutica no Brasil: Surgimento e desenvolvimento da indústria nacional. 2013. 66 f. Trabalho de Conclusão de Curso - Universidade Federal do Rio Grande do Sul, Porto Alegre. 2013.

FRENKEL, J. Estudo da competitividade de cadeias integradas no Brasil: impactos das zonas de livre comércio na cadeia farmacêutica. (Estudo coordenado pela equipe da Unicamp/IE demandado pelo MDIC e MCT/ FINEP). Campinas. Dezembro. 2002. 154 p.

GADELHA, C. A. G. Estudo da competitividade de cadeias integradas no Brasil: impactos das zonas de livre comércio: cadeia complexo da saúde, Campinas: Unicamp, 2002.

GADELHA, C. A. G. O complexo industrial da saúde e a necessidade de um enfoque dinâmico na economia da saúde. Ciência \& Saúde Coletiva. Rio de Janeiro: Abrasco,Vol. 8, n. 2, p. 521-535, 2003.

GADELHA, C. A. G.; COSTA, L. S. Saúde e desenvolvimento no Brasil: avanços e desafios. In: Revista de Saúde Pública da Universidade de São Paulo. Suplemento Saúde e Desenvolvimento. São Paulo: 2012. crossrefhttps://doi.org/10.1590/s0034-89102012005000062

GODOY, M R; OLIVEIRA, A L R; CÂMARA, Márcia Regina Gabardo. O Controle de Preços na Indústria Farmacêutica no Brasil. 2004, 25p. Disponível em: < http://edi.bnb.gov.br/content/aplicacao/ETENE/Anais/ docs/2004-o-controle-.pdf > Acesso em: 31/03/2014.

HASENCLEVER, L. Diagnóstico da indústria farmacêutica brasileira. Relatório de projeto desenvolvido em parceria Unesco/FUJB/Instituto de Economia/UFRJ: 2002; p. 1-57.

HASENCLEVER, Lia. O Mercado de Medicamentos Genéricos no Brasil. In: Simpósio Franco-Brasileiro O Novo Direito da Propriedade Intelectual no Domínio da Saúde e dos Seres Vivos (implicações para o acesso aos tratamentos anti-retrovirais), Brasília, 23-24 de Junho, 2004.

ISSE, K F. A indústria farmacêutica nacional e a importância dos medica- 
mentos genéricos no seu desenvolvimento. 2011. 77 f. Dissertação (Mestrado)- Universidade Federal do Rio Grande do Sul, Porto Alegre, 2011. IPDFARMA. Instituto de Pesquisa e Desenvolvimento de Fármacos e produtos Farmacêuticos. Disponível em: <http://www.ipd-farma.org.br $>$ Acesso em: 04/07/1014.

LEMOS, M.B.P.C. Indústria farmacêutica, propriedade intelectual e acesso a medicamentos: dilemas e perspectivas. 2008. 229 f. Dissertação (mestrado) - Pontíficia Universidade Católica de São Paulo, São Paulo. 2008.

LOBO, S.A. Características da Indústria Farmacêutica no Brasil durante o século XX: expansão e divisão internacional do trabalho. Revista Plurais Virtual, Goiás, v. 3, n. 1, 2013.

MAGALHÃES, L. C. G. Estrutura de mercado, estratégias de crescimento e de inovação e desempenho recente da indústria farmacêutica no Brasil. $253 \mathrm{f}$. Tese (Doutorado em Ciências Econômicas) - Instituto de Economia da Universidade Estadual de Campinas, Campinas, 2006.

MATIAS-PEREIRA, J. Política de proteção à propriedade intelectual no Brasil. In: ENANPAD, 27., 2003, Rio de Janeiro. Anais... Rio de Janeiro: ANPAD, 2003. p. $1-15$.

MOREIRA, N. V. A., ALMEIDA, F A S, COTA, M F M, SBRAGIA, R. A inovação tecnológica no Brasil: os avanços no marco regulatório e a gestão dos fundos setoriais. Revista de Gestão USP, São Paulo, v. 14, n. especial, p. 31-44, 2007.

MOTA, F. B.; CASSIOLATO, J E; GADELHA, C A G. Articulação da indústria farmacêutica brasileira com o exterior: há evidências de especialização regressiva?. Cad. Saúde Pública [online]. 2012. vol. 28, n.3, pp. 527-536. Disponível em: $<$ http://www.scielo.br/scielo.php? pid=S0102-311X2012000300013\&script $=$ sci abstract\&tlng =pt $>$. Acesso em: 21 de novembro de 2013.

NASSIF, A. Uma contribuição ao debate da nova política industrial brasileira. BNDES Setorial, Rio de Janeiro, setembro de 2003. (Texto para discussão, 101).

OLIVEIRA, N. B. Os fármacos e a saúde pública no Brasil: uma visão da cadeia produtiva. Parcerias Estratégicas, 20, Jun 2005.

PALMEIRA FILHO, P. L.; PAN, S. S. K. Cadeia Farmacêutica no Brasil: avaliação preliminar e perspectivas. BNDES Setorial, Rio de janeiro, v.18, p. 3-22, 2003. 
PALMEIRA FILHO, P., PIERONI, J. P., ANTUNES, A. M. S., MARTINS, J V. P. O desafio do financiamento à inovação farmacêutica no Brasil: a experiência do BNDES Profarma. Revista do BNDES, Rio de Janeiro, n. 37, p. 69-90, jun. 2012.

PALMEIRA FILHO, P L; CAPANEMA, L X L. A INDÚSTRIA farmacêutica nacional: Desafios rumo à inserção global. In: ALÉM, A C et al. O BNDES em um Brasil em transição. Rio de Janeiro: BNDES. 2010.

PIERONI, J. P.; PEREIRA, R. O.; MACHADO, L. Metodologia de Monitoramento e Avaliação do BNDES: Uma Aplicação para o Programa BNDES Profarma. BNDES Setorial, n. 33, p. 315-348, mar. 2011.

PIMENTEL, V., GOMES, R. LANDIM, A., MACIEL, M. PIERONI, J P. O desafio de adensar a cadeia de P\&D de medicamentos biotecnológicos no Brasil, BNDES Setorial, Rio de Janeiro, n. 38, p. 173-212, set. 2013.

PINHEIRO, M.A. Investimento e Price Caps num Mercado de Competição Imperfeita: uma abordagem estocástica em tempo contínuo. Dissertação (economia). Rio de Janeiro: PUC-RJ, 1999.

PIOVESAN, F; CARVALHO, P. L. de. Políticas para a implementação do direito ao acesso a medicamentos no Brasil. In: Revista Forense, vol. 398. Rio de Janeiro: Forense, jul-ago/2008. P. 63-90.

Pró-Genéricos. ASSOCIAÇÃO BRASILEIRA DAS INDÚSTRIAS DE MEDICAMENTOS GNÉRICOS - PRÓ-GENÉRICOS. Disponível em: < http:// www.progenericos.org.br>. Acesso em 01/05/2014.

RAMALHO, P I S. Transparência e participação social no processo regulatório da Anvisa: fortalecimento dos consumidores na regulação sanitária. In: PROENÇA, Jadir Dias; PRADO, Carlos Eduardo Resende (org). Melhoria da regulação no Brasil : o papel da participação e do controle social. $1^{a}$ Ed. Brasília: Presidência da República; 2011. p.187-207

REIS, C.; PIERONI, J. P.; SOUZA, J. O. B. Biotecnologia para saúde no Brasil. BNDES Setorial, Rio de Janeiro, n.32, p. 193-230, 2010.

REIS, C.; LANDIM, A.; PIERONI, J. P. Lições da Experiência Internacional e Propostas para a Incorporação da Rota Biotecnológica na Indústria Farmacêutica Brasileira, BNDES Setorial, Rio de Janeiro, n. 34, p. 5-44, set. 2011. 
RUIZ, R.; CALIARI, T.; Machado; AMARAL, P. V.; DOMINGUES, E P; ARAÚJO, R. Complexo Industrial da Saúde. In: DE NEGRI e LEMOS (Orgs.). O núcleo tecnológico da indústria brasileira. Brasília: IPEA, vol. 2, p. 1029-1174, 2011.

SACCARO JR, N L.. A regulamentação de acesso a recursos genéticos e repartição de benefícios: disputas dentro e fora do Brasil. Ambient. soc. [online]. 2011, vol.14, n.1, pp. 229-244. ISSN 1414-753X.

SANTOS, M. C. B. G., PINHO, M. Estratégias tecnológicas em transformação: um estudo da indústria farmacêutica brasileira. Gestão da Produção, São Carlos, v. 19, n. 2, 2012.

SILVA, H P. Estado, regulação e saúde: considerações sobre a regulação econômica do mercado de saúde suplementar. Revista Leituras de Economia Política, v. 7, n. 1, p. 193-226, 2003.

SILVA, J C L. Direito de acesso aos medicamentos no Brasil face à tutela jurídica das patentes farmacêuticas. In: Encontro para o Congresso Nacional do CONPEDI, $\mathrm{n}^{\circ}$ XVII, 2008, Salvador. Anais. Florianópolis: Fundação Boiteux, 2008, p. 43304349 .

SILVA, E N. Complexo Econômico-Industrial da Saúde. Tempus Actas de Saúde Coletiva, [S.l.], v. 8, n. 1, p. Pág. 57-62, mar. 2014.

SINDUSFARMA - Sindicato da Indústria de Produtos Farmacêuticos no Estado de São Paulo. 2014. Disponível em < http://www.sindusfarma.org.br/sindus_historia.shtml>. Acesso em: 16/01/2014.

SOARES, C. S.; CORONEL, D. A.; MARION FILHO, P. J.. A recente política industrial brasileira: da "Política de Desenvolvimento Produtivo" ao "Plano Brasil Maior”. Revista Perspectivas Contemporâneas, v. 8, n. 1, p. 1-20, jan./jun. 2013.

TACHINARDI, M. H. A guerra das patentes. São Paulo: Editora Paz e Terra, 1993.

TAVEIRA, R A V. Alinhamento entre a regulação sanitária e as políticas públicas de medicamentos no Brasil. Brasília, 2013. Dissertação (Mestrado em Ciências Farmacêuticas) - Faculdade de Ciências da Saúde, Universidade de Brasília, Brasília, 2013.

TRAJANO DA SILVA, P R S. Setor Farmacêutico: trajetórias de empresas líderes nos anos 90.2003. 85 f. Monografia (Trabalho de Conclusão de Cur- 
so). - Instituto de Economia, Universidade Estadual de Campinas, Campinas, 2003.

VARGAS, M. A.; BURD, P. Inovação na indústria química e biotecnológica em saúde: em busca de uma agenda virtuosa. In: VI Jornada Nacional de Economia da Saúde, 2012, Brasília. crossrefhttps://doi.org/10.1590/s003489102012000700006

VARGAS, M.; GADELHA, C. A. G.; COSTA, L. S.; MALDONADO, J. Inovação na indústria química e biotecnológica em saúde: em busca de uma agenda virtuosa. In: Revista de Saúde Pública da Universidade de São Paulo. Suplemento Saúde e Desenvolvimento. São Paulo: 2012. crossrefhttps:// doi.org/10.1590/s0034-89102012000700006

VALENTIM, J. Política de medicamentos genéricos: um estudo de caso brasileiro. 2003. 113 f. Dissertação (Mestrado em Ciência Econômica)- Instituto de Economia, Universidade Estadual de Campinas, Campinas, 2003.

Recebido em 24.11.15

Aprovado em 11.07.16 